\title{
KAJIAN WATER TABLE PADA SEMAI PEREPAT (Combretocarpus rotundatus Miq dan JELUTUNG (Dyera lowii Hook) DIINOKULASI Glomus sp 3 DI TANAH GAMBUT
}

\author{
Study Of Water Table In Seedlings Of Perepat (Combretocarpus rotundatus Miq) and \\ Jelutung (Dyera lowii Hook) Inoculated Glomus sp 3 In Peat Soil \\ Burhanuddin $^{1 *}$, Siti Kabirun ${ }^{2}$, Bostang Radjagukguk ${ }^{2}$, dan Sumardi ${ }^{3}$ \\ ${ }^{\prime}$ Fakultas Kehutanan, Universitas Tanjungpura Pontianak \\ Jl. Jend. A. Yani Kompleks Untan Benua Melayu Darat Pontianak Selatan \\ ${ }^{2}$ Fakultas Pertanian, Universitas Gadjah Mada Yogyakarta* \\ ${ }^{3}$ Fakultas Kehutanan, Universitas Gadjah Mada Yogyakarta* \\ *Kampus UGM Bulak Sumur - Yogyakarta 55281 \\ E-mail : hans_borneo@yahoo.co.id "Penulis untuk korespondensi
}

Naskah masuk : 26 Oktober 2010; Naskah diterima : 31 Mei 2011

\begin{abstract}
A study on the influence of water table on the growth Combretocarpus rotundatus Miq and Dyera lowii Hook inoculation with arbuscular mycorrhizal fungi (AMF) and fertilization SP 36 in peat soils was conducted in greenhouse Soil Sience Laboratory Faculty of Agriculture, is Gadjah Mada University in Yogyakarta for 14 weeks. The goal of research purpose wa to determine the effect of water table, $P$ fertilization and inoculation with AMF on the growth of C.rotundatus Miq and D.lowii Hook seedlings. Nursery experiments were conducted using Completely Randomized Factorial Design with three replications. Observations made on C.rotundatus Miq and D.lowii Hook seedlings 14 weeksof age after weaning include: height, diameter, number of leaves, shoot dry weight, and P uptake of plants after harvest. Experiments of water table, fertilized of $100 \mathrm{ppm} \mathrm{SP} 36$ and inoculated with Glomus sp 3 resulted in the best water table is $20 \mathrm{~cm}$ in C.rotundatus Miq and D.lowii Hook seedlings. In the water table $20 \mathrm{~cm}$ increase in growth of C.rotundatus Miq are $324.86 \%$ high, 366.67\% diameter, $437.50 \%$ number of leaves, $630.00 \%$ shoot dry weight and P uptake of $835.80 \%$. For D.lowii Hook are $107.61 \%$ high, $136.05 \%$ diameter, $42.01 \%$ number of leaves, shoot dry weight of $643.83 \%$ and $851.56 \%$ P uptake. It was concluded that inoculation with the AMF type of Glomus sp 3 combined with the provision of $P$ fertilizer dosage of $100 \mathrm{ppm}$ SP 36 and planting on water table level $20 \mathrm{~cm}$ and $10 \mathrm{~cm}$ can be used widely to improve growth of C. rotundatus Miq and D. lowii Hook seedling in the nursery.
\end{abstract}

Keywords: ex-PLG, peat,Water table, Glomus sp 3

\begin{abstract}
ABSTRAK
Penelitian pengaruh water table (jeluk muka air tanah) terhadap pertumbuhan perepat (Combretocarpus rotundatus Miq) dan jelutung (Dyera lowii Hook) dengan inokulasi jamur mikoriza arbuskula (JMA) dan pemupukan SP 36 di tanah gambut dilaksankan di rumah kaca laboratorium Ilmu Tanah Fakultas Pertanian Universeitas Gadjah Mada Yogyakarta selama 14 minggu. Tujuan penelitian untuk mengetahui pengaruh jeluk muka air tanah, pemupukan $\mathrm{P}$ dan inokulasi JMA terhadap pertumbuhan semai perepat dan jelutung. Percobaan persemaian menggunakan Rancangan Acak Lengkap Faktorial dengan tiga ulangan. Pengamatan dilakukan pada umur semai perepat dan jelutung 14 minggu setelah penyapihan yang meliputi: tinggi, diameter, jumlah daun, dan untuk berat kering pucuk dan serapan P tanaman dilakukan setelah panen. Percobaan pengujian jeluk muka air tanah pada semai perepat dan jelutung yang dipupuk SP 36 takaran 100 ppm dan diinokulasi dengan Glomus sp 3 membuktikan bahwa jeluk muka air tanah terbaik adalah $20 \mathrm{~cm}$. Pada jeluk muka air tanah $20 \mathrm{~cm}$ peningkatan pertumbuhan untuk perepat tinggi $324,86 \%$, diameter $366,67 \%$, jumlah daun $437,50 \%$, berat kering pucuk $630,00 \%$ dan serapan $\mathrm{P}$ $835,80 \%$. Untuk jelutung tinggi $107,61 \%$, diameter $136,05 \%$, jumlah daun $42,01 \%$, berat kering pucuk
\end{abstract}


643,83 \% dan serapan P 851,56 \%. Disimpulkan bahwa inokulasi dengan JMA jenis Glomus sp 3 yang dikombinasikan dengan pemberian pupuk $P$ takaran $100 \mathrm{ppm}$ dan penanaman pada jeluk muka air tanah $20 \mathrm{~cm}$ dan $10 \mathrm{~cm}$ dapat dimanfaatkan secara luas untuk meningkatkan pertumbuhan bibit perepat $(C$. rotundatus Miq) dan jelutung (D.lowii Hook) di persemaian.

\section{Kata kunci : ex-PLG, gambut, Glomus sp 3, Water table}

\section{PENDAHULUAN}

Pada tahun 1995 telah dilakukan pembukaan lahan gambut di Kalimantan Tengah yang dikenal dengan Pengembangan Lahan Gambut Sejuta Hektar (PLG atau Mega Rice ProjectMRP) yang luas totalnya 1.457 .100 hektar. Pembukaan lahan ini disertai dengan pembuatan kanal. Akibat pembuatan kanal dengan total panjang 2.008,7 km dengan berbagai ukuran lebar dan kedalaman, telah terjadi kerusakan status hidrologi kawasan secara drastis yaitu terjadi pengatusan sangat berlebihan serta rendahnya retensi air dan jeluk muka air tanah. Takahashi et al. (2002) memaparkan perubahan yang terjadi pada jeluk muka air tanah di blok $\mathrm{C}$ ex-PLG, di musim penghujan saja jeluk muka air tanah bisa mencapai $5 \mathrm{~cm} \mathrm{-} 50 \mathrm{~cm}$ yang seharusnya pada kondisi normal pada musim penghujan bisa tergenang dengan ketinggian 100 $\mathrm{cm}$ dari atas permukaan tanah.

Pada tahun 2005 Centre for International Co-operation in Sustainable Management of Tropical Peatlands (CIMTROP) Universitas Palangkaraya, bekerjasama dengan masyarakat Uni Eropa melakukan restorasi hidrologi dengan pembuatan dam atau pembendungan kanal-kanal yang mengering di blok C Kelampangan. Menurut Limin et al. (2008) perubahan yang terjadi pada jeluk muka air tanah sebelum dan sesudah pembendungan kanal di blok C ex-PLG, pada bulan-bulan tertentu terjadi perubahan jeluk muka air tanah yang meningkat, seperti yang terjadi pada bulan Agustus 2005 (sebelum pembendungan pada bulan Nopember 2004 jeluk muka air tanah mencapai $112 \mathrm{~cm}$, setelah pembendungan pada bulan Agustus 2005 jeluk muka air tanah hanya $9 \mathrm{~cm}$ ).

Menurut Ritzema et al. (2008) jeluk muka air tanah gambut pada musim kemarau bisa mencapai $40 \mathrm{~cm}$ di bawah permukaan, sedangkan pada musim hujan mencapai $100 \mathrm{~cm}$ dari atas permukaan tanah. Selanjutnya menurut Ritzema et al. (2008) meskipun restorasi hidrologi dengan pembendungan kanal tidak menunjukkan perubahan jeluk muka air tanah yang signifikan, tetapi pembendungan kanal sangat berperan penting dalam proses rehabilitasi lahan gambut seperti mengurangi subsiden, mengurangi emisi karbon, mengurangi kebakaran dan dalam jangka panjang dapat memulihkan hutan rawa gambut secara alami.

Berdasarkan kenyataan tersebut di atas, maka dipandang sangat penting untuk dilakukan perbaikan melalui suatu upaya konservasi yaitu dengan melakukan pemulihan pada lahan gambut tersebut dengan campur tangan manusia. Namun demikian, kegiatan pemulihan ini akan selalu berhadapan dengan masalah yang disebabkan oleh pembukaan lahan gambut tersebut diantaranya: (1) permukaan air tanah menyusut, (2) terjadi kekeringan, (3) $\mathrm{pH}$ tanah asam, (4) miskin unsur hara dan (5) aktivitas mikroorganisme rendah. Untuk mengatasi kendalakendala tersebut, perlu diusahakan suatu teknologi alternatif yang tepat yaitu dengan pupuk hayati (biofertilizer). Pupuk hayati telah berhasil dikembangkan di negara-negara maju sebagai pupuk yang potensial dan aman bagi lingkungan, salah satu diantaranya adalah Jamur Mikoriza Arbuskula (JMA) (Gumbira-Said, 1996; Mendoza et al. 2005; Leigh et al. 2008; Garcia \& Mendoza, 2008; Cornejo et al. 2008; Cardoso et al. 2009).

Penelitian yang mengungkap peranan JMA dalam meningkatkan pertumbuhan telah banyak dilakukan pada berbagai tanaman hutan, yaitu pulai, bungur, mangium, dan sungkai (Martin et al. 2004), Shorea balangeran (Turjaman et al. 2007), ramin (Muin, 2003), jati (Faridah, 1999), Aquilaria microcarpa (Santoso et al. 2007), Acacia crassicarpa (Pidjath et al. 2007), dan Vitex cofassus (Prayudyaningsih \& Santoso, 2007). Pada perepat (Combretocarpus rotundatus Miq) dan jelutung (Dyera lowii Hook), penelitian JMA ini belum banyak dilakukan.

Perepat adalah salah satu jenis asli hutan rawa gambut yang dapat tumbuh baik pada kondisi terbuka. Sebagaimana yang dijelaskan Saito et al. (2002) bahwa jenis perepat, gerunggang (Cratoxylon arborescen) dan asam- 
asam (Mangifera sp) dapat tumbuh baik pada tempat-tempat terbuka, tahan kekeringan dan tahan terhadap suhu tanah yang tinggi. Lebih lanjut dijelaskan bahwa jenis perepat, gerunggang dan asam-asam merupakan jenis cepat tumbuh di hutan rawa gambut (Saito et al. 2002). Jelutung juga merupakan jenis asli yang tumbuh di hutan rawa gambut. Jenis ini merupakan jenis pohon dwiguna, yang cocok untuk ditanam pada lahan gambut yang akan dikonservasi. Jelutung hanya akan dimanfaatkan dari hasil ikutannya saja berupa getah jelutung.

Hasil penelitian Burhanuddin et al. (2010) membuktikan bahwa jenis JMA Glomus sp 3 yang terbaik meningkatakan pertumbuhan semai perepat dari beberapa jenis JMA yang diuji pada media gambut. Selanjutnya dijelaskan pula bahwa tanaman perepat yang dipupuk dengan pupuk SP 36 takaran 100 ppm dan diinokulasi Glomus sp 3 adalah takaran pupuk terbaik meningkatkan pertumbuhan semai perepat pada media gambut (Buranuddin, 2011). Demikian juga pada tanaman jelutung yang dipupuk dengan batuan fosfat takaran $100 \mathrm{ppm}$ dan diinokulasi Glomus sp 3 adalah yang terbaik meningkatkan pertumbuhan jelutung pada media gambut (Burhanuddin, 2001).

Tujuan dari penelitian ini adalah untuk mengetahui pengaruh jeluk muka air tanah, pemupukan $\mathrm{P}$ dan inokulasi JMA terhadap pertumbuhan semai perepat dan jelutung pada tanah gambut.

\section{BAHAN DAN METODE}

\section{A. Bahan Penelitian}

Penelitian yang dilaksanakan pada bulan April 2009 Agustus 2009, di rumah kaca Laboratorium Ilmu Tanah Fakultas Pertanian Universitas Gadjah Mada menggunakan; a). benih perepat $(C$. rotundatus) dan jelutung $(D$. lowii) rawa yang berasal dari tegakan alam blok $\mathrm{C}$ exPLG Kalampangan Palangkaraya, b). Pupuk Sp 36 dan c). JMA jenis Glomus sp 3.

\section{B. Metode Penelitian}

Penelitian ini menggunakan metode eksperimen murni dengan rancangan perlakuan faktorial yang disusun dalam Rancangan Acak Kelompok ( $2 \times 7)$ dengan perlakuan jenis pohon dan jeluk muka air tanah (water table) dan ulangan sebanyak 3 kali. Jeluk muka air tanah (water table) diatur bervariasi dari $0 \mathrm{~cm}$ sampai
$40 \mathrm{~cm}$ dengan interval $10 \mathrm{~cm}$. Tanah dengan berbagai jeluk muka air tanah tersebut dipupuk dengan 100 gram SP 36 dan diinokulasi JMA jenis Glomus sp 3. Selain itu disertakan pula tanah dalam kondisi tergenang air $1 \mathrm{~cm}$ tanpa dipupuk dan tidak diinokulasi JMA sebagai kontrol.

\section{Tahapan PelaksanaanPenelitian}

Benih perepat dan jelutung dikecambahkan dalam bak kecambah yang berisi media gambut yang sudah steril. Setelah semai berumur satu bulan, dilakukan penyapihan. Selanjutnya semai ditanam dalam kantong plastik hitam ukuran 2,5 kg yang telah diisi media gambut steril. Pupuk basal diberikan dalam bentuk larutan yang terdiri dari $70 \mathrm{ppm} \mathrm{NH}_{4} \mathrm{NO}_{3}, 35 \mathrm{ppm}$ $\mathrm{KH}_{2} \mathrm{PO} 4,70$ ppm K $\mathrm{SO}_{4}, 70$ ppm $\mathrm{CaCl}_{2}, 22$ ppm $\mathrm{CuSO}_{4} \cdot 5 \mathrm{H}_{2} \mathrm{O}, 5 \mathrm{ppm} \mathrm{ZnSO}_{4} \cdot 7 \mathrm{H}_{2} \mathrm{O} 10 \mathrm{ppm}$ $\mathrm{MnSO}_{4} \cdot 7 \mathrm{H}_{2} \mathrm{O}, 0,33 \mathrm{ppm} \mathrm{CoSO} \mathrm{C}_{4} \cdot 7 \mathrm{H}_{2} \mathrm{O}, 0,20 \mathrm{ppm}$ $\mathrm{NaMoO}_{4} \cdot 2 \mathrm{H}_{2} \mathrm{O}$, dan $20 \mathrm{ppm} \mathrm{MgSO} \cdot 7 \mathrm{H}_{2} \mathrm{O}$.

Tanaman ditumbuhkan selama 14 minggu setelah penyapihan, di rumah kaca Laboratorium Ilmu Tanah Fakultas Pertanian Universitas Gadjah Mada. Data yang dikumpulkan terdiri dari tinggi $(\mathrm{cm})$, diameter pangkal batang $(\mathrm{mm})$, jumlah daun (helai), berat kering pucuk (gram), dan serapan hara P tanaman.

\section{Analisis Data}

Data tinggi, diameter, jumlah daun, berat kering pucuk dan serapan hara $\mathrm{P}$ tanaman dianalisis menurut analisis keragaman (ANOVA) rancangan acak kelompok menggunakan metoda SAS X3.

\section{HASIL DAN PEMBAHASAN}

\section{A. Hasil}

Pertumbuhan semai perepat dan jelutung dinilai berdasarkan pengamatan terhadap pertumbuhan tinggi, diameter, jumlah daun, berat kering pucuk dan serapan P tanaman. Hasil analisis keragaman pengaruh faktor perlakuan disajikan dalam Tabel 1, 2, 3, 4 dan 5 .

Tabel 1. Hasil sidik ragam pengaruh jeluk muka air tanah dengan pemupukan SP 36 dan inokulasi JMA terhadap tinggi semai perepat dan jelutung (The results of analysis variance of influence of water table with SP 36 fertilization and AMF inoculation for hight C. rotundatus and D.lowii seedling). 
Tabel (Table)1. Hasil sidik ragam pengaruh jeluk muka air tanah dengan pemupukan SP 36 dan inokulasi JMA terhadap tinggi semai perepat dan jelutung (The results of analysis variance of influence of water table with SP 36 fertilization and AMF inoculation for hight C. rotundatus and D.lowii seedling)

\begin{tabular}{|l|c|r|r|r|r|}
\hline $\begin{array}{c}\text { Sumber keragaman } \\
\text { (Source of variance) }\end{array}$ & $\begin{array}{c}\text { Derajat bebas } \\
\text { (Degrees of } \\
\text { freedom) }\end{array}$ & $\begin{array}{c}\text { Jumlah kuadrat } \\
\text { (Sum of Squares) }\end{array}$ & $\begin{array}{c}\text { Kuadrat tengah } \\
\text { (Mean Squares) }\end{array}$ & $\begin{array}{c}\text { F hitung } \\
(\text { F cale) }\end{array}$ & Pr > F \\
\hline Ulangan & 2 & 18,18 & 9,09 & $0,73^{\text {th }}$ & 0,4893 \\
Pohon (J) & 1 & 9223,37 & 9223,37 & $745,64^{*}$ & 0,0001 \\
Jeluk (W) & 6 & 4172,17 & 695,36 & $56,21^{*}$ & 0,0001 \\
$\mathrm{~J} * \mathrm{~W}$ & 6 & 2192,19 & 365,36 & $29,54^{*}$ & 0,0001 \\
Galat & 26 & 321,61 & 12,36 & \\
\hline
\end{tabular}

Total 15927,53

$\overline{\mathrm{CV}}=12,22 \quad$ Keterangan $($ Remarks $) *=$ Signifikan $($ Significant $)$

$\mathrm{tn}=$ tidak berbeda nyata (Non-significant)

Tabel (Table) 2. Hasil sidik ragam pengaruh jeluk muka air tanah dengan pemupukan SP 36 dan inokulasi JMA terhadap diameter semai perepat dan jelutung (The results of analysis variance of influence of water table with SP 36 fertilization and AMF inoculation for diameter $C$. rotundatus and D. lowii seedling)

\begin{tabular}{|l|c|r|r|r|r|}
\hline Sumber keragaman & $\begin{array}{c}\text { Derajat bebas } \\
\text { (Degrees of } \\
\text { freedom) }\end{array}$ & $\begin{array}{c}\text { Jumlah kuadrat } \\
\text { (Sum of Squares) }\end{array}$ & $\begin{array}{c}\text { Kuadrat tengah } \\
\text { (Mean Squares) }\end{array}$ & $\begin{array}{c}\mathrm{F} \text { hitung } \\
\text { (F cale) }\end{array}$ & $\operatorname{Pr}>\mathrm{F}$ \\
\hline Ulangan & 2 & 3,25 & 1,62 & $4,57^{*}$ & 0,0100 \\
Pohon (J) & 1 & 0,21 & 0,21 & $0,60^{*}$ & 0,0001 \\
Jeluk (W) & 6 & 98,05 & 16,34 & $45,94^{*}$ & 0,0001 \\
$\mathrm{~J} * \mathrm{~W}$ & 6 & 18,36 & 3,06 & $8,61^{*}$ & 0,0001 \\
Galat & 26 & 9,25 & 0,35 & & \\
\hline
\end{tabular}

Total 41

129,14

$\mathrm{CV}=13,68 \quad$ Keterangan $($ Remarks $) *=$ Signifikan $($ Significant $)$

Tabel (Table) 3. Hasil sidik ragam pengaruh jeluk muka air tanah dengan pemupukan SP 36 dan inokulasi JMA terhadap jumlah daun semai perepat dan jelutung (The results of analysis variance of influence of water table with SP 36 fertilization and AMF inoculation for number of leaves $C$. rotundatus and D. lowii seedling)

\begin{tabular}{|c|c|c|c|c|c|}
\hline Sumber keragaman & $\begin{array}{c}\text { Derajat bebas } \\
\text { (Degrees of } \\
\text { freedom) }\end{array}$ & $\begin{array}{c}\text { Jumlah kuadrat } \\
\text { (Sum of Squares) }\end{array}$ & $\begin{array}{l}\text { Kuadrat tengah } \\
\text { (Mean Squares) }\end{array}$ & $\begin{array}{l}\text { F hitung } \\
(F \text { cale })\end{array}$ & $\operatorname{Pr}>F$ \\
\hline Ulangan & 2 & 69,85 & 34,92 & $1,43^{\text {tn }}$ & 0,2567 \\
\hline Pohon $(\mathrm{J})$ & 1 & 1303,71 & 1303,71 & $53,51 *$ & 0,0001 \\
\hline Jeluk (W) & 6 & 1623,57 & 270,59 & $11,11^{*}$ & 0,0001 \\
\hline $\mathrm{J} * \mathrm{~W}$ & 6 & 1323,95 & 220,65 & $9,06^{*}$ & 0,0001 \\
\hline Galat & 26 & 633,47 & 24,36 & & \\
\hline Total & 41 & 4954,57 & & & \\
\hline
\end{tabular}

Pada Tabel 1, 2, 3, 4 dan 5 memperlihatkan bahwa perlakuan water table dengan pemupukan SP 36 dan inokulasi dengan jenis JMA mem-berikan pengaruh yang sangat nyata terhadap semua parameter yang diuji yaitu; tinggi, diameter, jumlah daun, berat kering pucuk dan serapan P tanaman. Secara umum, perlakuan water table dengan pemberian pupuk SP 36 dan inokulasi jenis JMA mempengaruhi pertumbuhan semai perepat dan jelutung di persemaian. Perbedaan tanggap tinggi semai perepat dan jelutung terhadap tiap jeluk muka air tanah umur 14 minggu setelah penyapihan disajikan dalam Gambar 1. Tinggi semai perepat berbeda nyata terhadap jeluk muka air tanah 10 $\mathrm{cm}, 40 \mathrm{~cm}, 0 \mathrm{~cm}, 30 \mathrm{~cm}$ dan $20 \mathrm{~cm}$ dibandingkan dengan tanaman kontrol. Peningkatan tinggi semai perepat pada jeluk muka air tanah $10 \mathrm{~cm}$, 
$40 \mathrm{~cm}, 0 \mathrm{~cm}, 30 \mathrm{~cm}$, dan $20 \mathrm{~cm}$ berturut-turut lebih besar 132,35\%, 162,22\%, 182,67\%, $237,83 \%$, dan $324,86 \%$ dibandingkan dengan tanaman kontrol. Tinggi semai jelutung berbeda nyata terhadap jeluk muka air tanah $30 \mathrm{~cm}, 0 \mathrm{~cm}$, $10 \mathrm{~cm}$ dan $20 \mathrm{~cm}$ dibandingkan dengan tanaman kontrol. Peningkatan tinggi semai jelutung pada jeluk muka air tanah $30 \mathrm{~cm}, 0 \mathrm{~cm}, 10 \mathrm{~cm}$, dan 20 cm berturut-turut lebih besar 77,61\%,83,75\%, $102,27 \%$, dan $107,61 \%$ dibandingkan dengan tanaman kontrol.

Tabel (Table) 4. Hasil Hasil sidik ragam pengaruh jeluk muka air tanah dengan pemupukan SP 36 dan inokulasi JMA terhadap berat kering pucuk semai perepat dan jelutung (The results of analysis variance of influence of water table with SP 36 fertilization and AMF inoculation for shoot dry weight C. rotundatus and D. lowii seedling)

\begin{tabular}{|l|c|r|r|r|r|}
\hline Sumber keragaman & $\begin{array}{c}\text { Derajat bebas } \\
\text { (Degrees of } \\
\text { freedom })\end{array}$ & $\begin{array}{c}\text { Jumlah kuadrat } \\
\text { (Sum of Squares) }\end{array}$ & $\begin{array}{c}\text { Kuadrat tengah } \\
\text { (Mean Squares) }\end{array}$ & $\begin{array}{c}\text { F hitung } \\
(F \text { cale })\end{array}$ & $\operatorname{Pr}>\mathrm{F}$ \\
\hline Ulangan & 2 & 22,75 & 11,37 & $2,46^{\mathrm{th}}$ & 0,1052 \\
Pohon (J) & 1 & 224,02 & 224,02 & $48,41^{*}$ & 0,0001 \\
Jeluk (W) & 6 & 314,05 & 52,34 & $11,31^{*}$ & 0,0001 \\
J*W & 6 & 216,26 & 36,04 & $7,79 *$ & 0,0001 \\
Galat & 26 & 120,31 & 4,62 & & \\
\hline
\end{tabular}

$\mathrm{CV}=45.08$

Keterangan $(\text { Remarks })^{*}=$ Signifikan $($ Significant $)$

tn $=$ tidak berbeda nyata (Non-significant)

Tabel (Table) 5. Hasil sidik ragam pengaruh jeluk muka air tanah dengan pemupukan SP 36 dan inokulasi JMA terhadap serapan P semai perepat dan jelutung (The results of analysis variance of influence of water table with SP 36 fertilization and AMF inoculation for P uptake $C$. rotundatus and D. lowii seedling)

\begin{tabular}{|l|c|r|r|r|r|}
\hline Sumber keragaman & $\begin{array}{c}\text { Derajat bebas } \\
\text { (Degrees of } \\
\text { freedom) }\end{array}$ & $\begin{array}{c}\text { Jumlah kuadrat } \\
\text { (Sum of Squares) }\end{array}$ & $\begin{array}{c}\text { Kuadrat tengah } \\
\text { (Mean Squares) }\end{array}$ & $\begin{array}{c}\text { F hitung } \\
\text { (F cale) }\end{array}$ & $\operatorname{Pr}>\mathrm{F}$ \\
\hline Ulangan & 1 & 3044,53 & 3044,53 & $37,13^{*}$ & 0,0001 \\
Pohon (J) & 6 & 4392,59 & 732,09 & $8,93^{*}$ & 0,0001 \\
Jeluk (W) & 6 & 2533,68 & 422,28 & $5,15^{*}$ & 0,0011 \\
$\mathrm{~J} * \mathrm{~W}$ & 26 & 2295,85 & & & \\
Galat & 41 & 12266,67 & \\
\hline
\end{tabular}

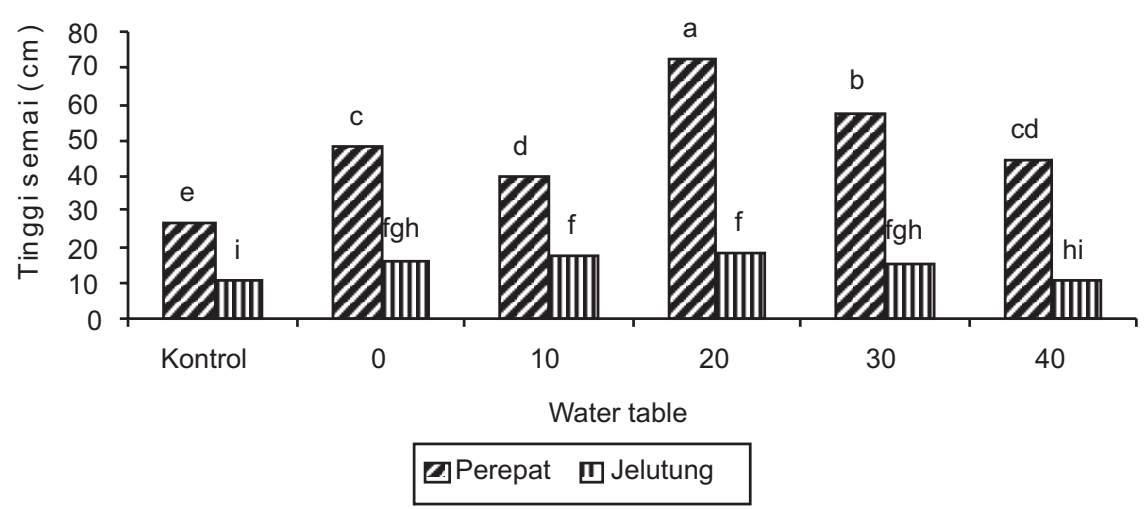

Keterangan (Remarks): Huruf yang sama pada histogram tidak berbeda nyata berdasarkan uji jarak berganda Duncan taraf 5 persen (Bars with the same letter are not significantly different based on Duncan's multiple range test $(0,05)$

Gambar(Figure) 1. Pengaruh water table, pupuk SP 36 dan inokulasi JMA terhadap tinggi semai perepat dan jelutung (Effect of water table, SP 36 fertilization and AMF inoculation for height on C.rotundatus and D. lowii seedling) 
Diameter semai perepat berbeda nyata terhadap jeluk muka air tanah $40 \mathrm{~cm}, 10 \mathrm{~cm}, 0$ $\mathrm{cm} 30 \mathrm{~cm}$ dan $20 \mathrm{~cm}$ dibandingkan dengan tanaman kontrol (Gambar 2). Peningkatan diameter semai perepat pada jeluk muka air tanah 40 $\mathrm{cm}, 10 \mathrm{~cm}, 0 \mathrm{~cm}, 30 \mathrm{~cm}$, dan $20 \mathrm{~cm}$ berturut-turut lebih besar 166,67\%, 188,67\%, 244,67\%, $311,33 \%$ dan $366,67 \%$ dibandingkan dengan tanaman kontrol. Diameter semai jelutung berbeda nyata terhadap jeluk muka air tanah 30 $\mathrm{cm}, 0 \mathrm{~cm}, 20 \mathrm{~cm}$, dan $10 \mathrm{~cm}$ dibandingkan dengan tanaman kontrol. Peningkatan diameter semai jelutung pada jeluk muka air tanah $30 \mathrm{~cm}, 0 \mathrm{~cm}$, $20 \mathrm{~cm}$, dan $10 \mathrm{~cm}$ berturut-turut lebih besar 93,13 $\%, 136,05 \%, 136,05 \%$, dan $186,26 \%$ dibandingkan dengan tanaman kontrol.

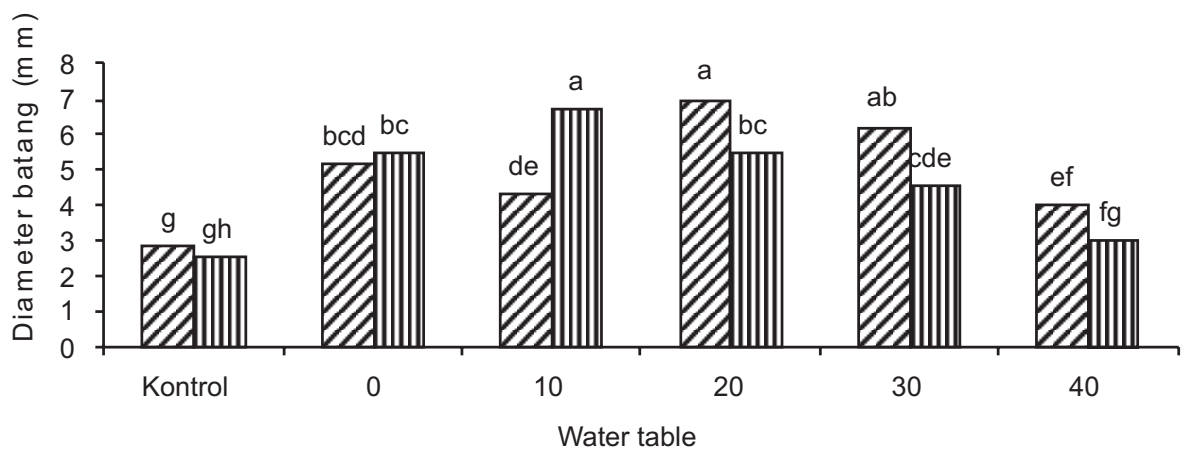

$$
\text { 乙Perepat 而Jelutung }
$$

Keterangan (Remarks) : Huruf yang sama pada histogram tidak berbeda nyata berdasarkan uji jarak berganda Duncan taraf 5 persen (Bars with the same letter are not significantly different based on Duncan's multiple range test $(0,05)$

Gambar(Figure) 2. Pengaruh water table, pupuk SP 36 dan inokulasi JMA terhadap diameter semai perepat dan jelutung (Effect of water table, SP 36 fertilization and AMF inoculation

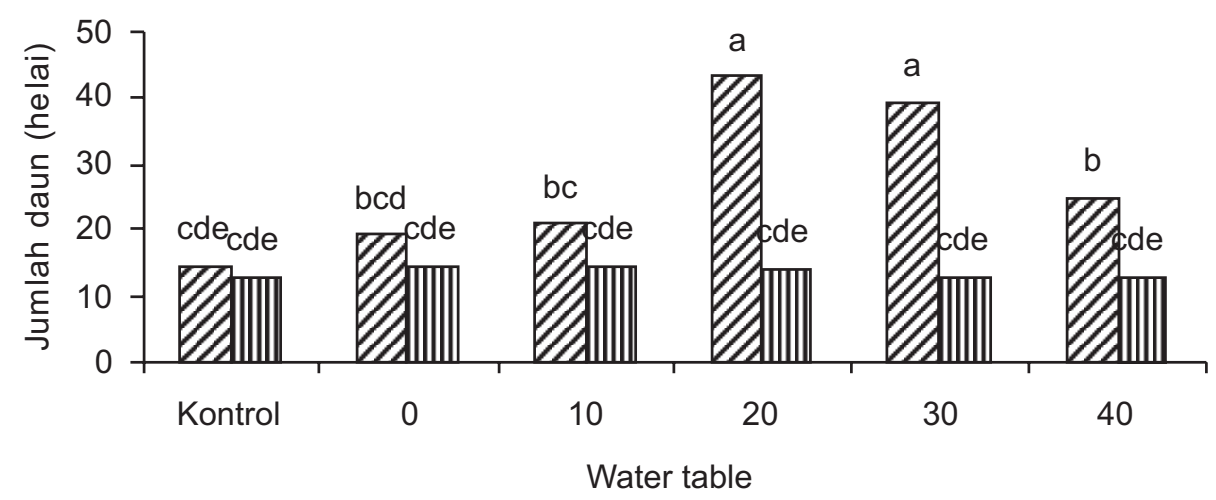

¿]Perepat IIIJelutung

Keterangan (Remarks): Huruf yang sama pada histogram tidak berbeda nyata berdasarkan uji jarak berganda Duncan taraf 5 persen (Bars with the same letter are not significantly different based on Duncan's multiple range test $(0,05)$

Gambar(Figure) 3. Pengaruh water table, pupuk SP 36 dan inokulasi JMA terhadap jumlah daun semai perepat dan jelutung (Effect of water table, SP 36 fertilization and AMF inoculation for number ofleaves on C.rotundatus and D.lowii seedling)

Perbedaan tanggap berat kering pucuk semai perepat dan jelutung terhadap tiap jeluk muka air tanah umur 14 minggu setelah penyapihan disajikan dalam Gambar 4. Berat kering pucuk semai perepat berbeda nyata terhadap jeluk muka air tanah $30 \mathrm{~cm}$ dan $20 \mathrm{~cm}$ dibandingkan dengan tanaman kontrol. Peningkatan berat kering pucuk semai perepat pada jeluk muka air tanah $30 \mathrm{~cm}$ dan $20 \mathrm{~cm}$ berturut-turut lebih besar 534,76\% dan 630,00\% 
dibandingkan dengan tanaman kontrol. Berat kering pucuk semai jelutung berbeda nyata terhadap jeluk muka air tanah $20 \mathrm{~cm}$ dibandingkan dengan tanaman kontrol. Peningkatan berat kering pucuk semai jelutung pada jeluk muka air tanah $20 \mathrm{~cm}$ sebesar 643,83

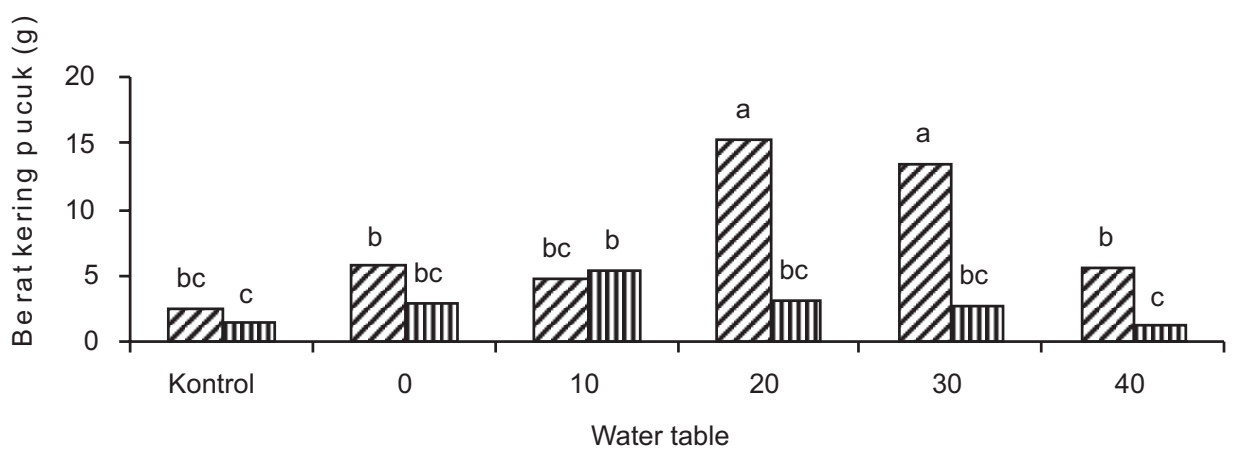

¿Perepat 四Jelutung

Keterangan (Remark): Huruf yang sama pada histogram tidak berbeda nyata berdasarkan uji jarak berganda Duncan taraf 5 persen (Bars with the same letter are not significantly different based on Duncan's multiple range test $(0,05)$

Gambar(Figure) 4. Pengaruh water table, pupuk SP 36 dan inokulasi JMA terhadap berat kering pucuk semai perepat dan jelutung (Effect of water table, SP 36 fertilization and AMF inoculation for shoot dry weight on C.rotundatus and D.lowii seedling)

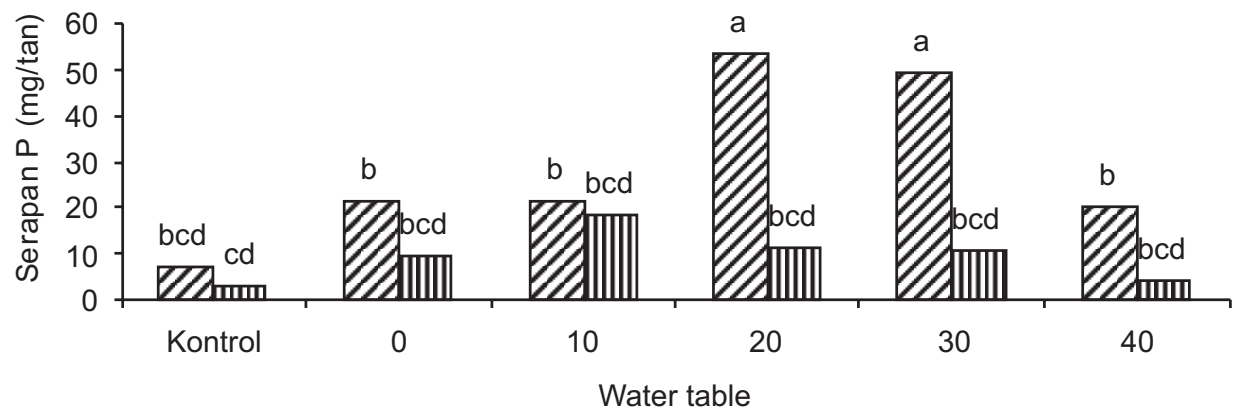

¿.Perepat $\square$ Jelutung

Keterangan(Remark): Huruf yang sama pada histogram tidak berbeda nyata berdasarkan uji jarak berganda Duncan taraf 5 persen (Bars with the same letter are not significantly different based on Duncan's multiple range test $(0,05)$.

Gambar(Figure) 5. Pengaruh water table, pupuk SP 36 dan inokulasi JMA terhadap serapan P semai perepa dan jelutung (Effect of water table, SP 36 fertilization and AMF inoculation for Puptake on C.rotundatus and D. lowii seedling)

Serapan P tanaman perepat berbeda nyata terhadap jeluk muka air tanah $30 \mathrm{~cm}$ dan $20 \mathrm{~cm}$ dibandingkan dengan tanaman kontrol (Gambar 5). Peningkatan serapan $P$ tanaman perepat pada jeluk muka air tanah $30 \mathrm{~cm}$ dan $20 \mathrm{~cm}$ berturutturut sebesar 761,19\% dan 835,80\% dibandingkan dengan tanaman kontrol. Serapan P tanaman jelutung tidak berbeda nyata, akan tetapi pada jeluk muka air tanah $10 \mathrm{~cm}$ cenderung meningkat sebesar 851,56\% dibandingkan dengan tanaman kontrol.

\section{B. Pembahasan}

Hasil penelitian ini membuktikan bahwa semai perepat dan jelutung meningkat pertumbuhannya dengan pengatuan water table dan pemupukan SP 36 takaran 100 ppm yang diinokulasi dengan jenis JMA. Hal ini diduga adanya asosiasi JMA endemik pada tanaman lokal gambut dapat meningkatkan pertumbuhan perepat dan jelutung. Hal ini sesuai dengan pendapat Maki et al. (2008) jenis JMA endemik 
setempat dapat memberikan hasil yang signifikan dalam meningkatkan pertumbuhan tanaman lokal pada tanah sulfat masam $\mathrm{pH} 3,4$.

Hasil pengujian jeluk muka air tanah gambut membuktikan bahwa untuk pemulihan hidrologi dengan melakukan pembendungan kanal tidak harus dengan penggenangan, karena sifat tanah gambut yang tidak bisa balik (irreversible) akan menyebabkan lapisan atas tanah gambut akan hanyut terbawa air yang menyebabkan cepatnya penurunan tanah gambut (subsidence). Hasil penelitian membuktikan bahwa jika akan memulihkan lahan gambut dengan melakukan penanaman dengan tanaman perepat bisa dilakukan dengan pengaturan jeluk muka air tanah mulai dari $40 \mathrm{~cm}, 30 \mathrm{~cm}, 20 \mathrm{~cm}$, dan $10 \mathrm{~cm}$, namun jeluk muka air tanah terbaik untuk tanaman perepat adalah jeluk muka air tanah $20 \mathrm{~cm}$. Jika lahan gambut akan ditanami dengan tanaman jelutung dapat dilakukan dengan pengaturan jeluk muka air tanah mulai dari 20 $\mathrm{cm}, 10 \mathrm{~cm}$, dan tergenang $1 \mathrm{~cm}$, dan yang terbaik pada jeluk muka air tanah $10 \mathrm{~cm}$. Hal ini sesuai dengan sifat alami dari tanaman jelutung yang tumbuh baik pada kondisi dibawah naungan dan merupakan jenis yang masuk pada tahap sesudah jenis-jenis dalam kelompok tipe hutan riverine forest (Page et al. 1999). Lebih lanjut menurut Shepherd et al. (1995), dan Page et al. (1999) jenis jelutung ada pada tipe hutan mixed swamp forest, tipe hutan transition forest, dan tipe hutan tall interior forest. Dengan mengetahui jeluk muka air tanah yang sesuai untuk tanaman perepat dan jelutung dapat dimanfaatkan untuk memulihkan tanah gambut dengan jenis-jenis lain yang satu kelompok dengan perepat misalnya Cratoxylon arborescens, Campnosperma auriculata, dan Palaquium leiocarpum, serta yang satu kelompok dengan jelutung isalnya Shorea balangreran, Shorea teysmanniana, dan Gonystylus bancanus (Page et al. 1999). Hasil penelitian jeluk muka air tanah juga dapat digunakan untuk pemanfaatan lahan gambut ex-PLG secara optimal, yaitu dengan mengatur jeluk muka air tanah $30 \mathrm{~cm}$ untuk penanaman perepat, lahan gambut ex-PLG bisa ditanami dengan tanaman campuran tanaman pertanian.

\section{KESIMPULAN DAN SARAN}

\section{A. Kesimpulan}

Hasil percobaan membuktikan bahwa pengujian jeluk muka air tanah pada semai perepat dan jelutung yang dipupuk SP 36 takaran 100 ppm dan diinokulasi JMA jenis Glomus sp 3 membuktikan jeluk muka air tanah terbaik $20 \mathrm{~cm}$, kemudian diikuti jeluk muka air tanah $30 \mathrm{~cm}$.

\section{B. Saran}

Secara umum dapat disarankan bahwa;

1. JMA jenis Glomus sp 3 yang dikombinasikan dengan pemberian pupuk $\mathrm{P}$ takaran $100 \mathrm{ppm}$ dan ditanam pada jeluk muka air tanah $20 \mathrm{~cm}$ dapat dimanfaatkan secara luas meningkatkan bibit perepat (C. rotundatus Miq) dan jelutung (D.lowii Hook) di persemaian.

2. Guna pemulihan lahan gambut khususnya EX-PLG Palangkaraya disarankan untuk memanfaatkan pupuk hayati JMA jenis Glomus sp 3 diinokulasikan pada perepat dan ditanam pada jeluk muka air tanah $20 \mathrm{~cm}$ atau $30 \mathrm{~cm}$ di lapanagn.

3. Untuk tanaman jelutung disarankan ditanamn pada jeluk muka air tanah mulai dari $20 \mathrm{~cm}, 10$ $\mathrm{cm}$ dan tergenang $1 \mathrm{~cm}$ di lapangan.

\section{DAFTAR PUSTAKA}

Burhanuddin., S. Kabirun., B. Radjagukguk. \& Sumardi. 2010. Effect of AMF Inoculation on the Growth of Combretocarpus rotundatus Miq on a Peat Soil from Central Kalimantan (For Restoration Ex-Mega Rice Project Central Kalimantan). Jurnal Biota Vol.15 (1): 63-71.

Burhanuddin. 2011. Kajian Takaran Pupuk SP 36 pada Perepat (Combretocarpus rotundatus Miq) dengan Inokulasi Mikoriza di Tanah Gambut. Jurnal VOKASI. VOL. 7 (2): 166-178.

Burhanuddin. 2011. Mycorrhizal Symbioses with Jelutung (Dyera lowii Hook) under Increasing Phosphate Rock Levels in Peat Soil. Jurnal BELIAN. VOL. 10 (2): 135144.

Cardoso, JA., de Lemos., EEP., dos Santos, TMC., Caetano, LC. \& Nogueira, MA. 2009. Mycorrhizal Dependency of Mangaba Tree under Increaing Phosphorus Levels. Pesquisa Agropecuaria Brasileira. 43(7): 887-892.

Cornejo, P., R. Rubio., C. Castillo., R. Azeon. \& F. Borie. 2008. Mycorrhizal Effectiveness on Wheat Nutrient Acquisition in an Acidic Soil from Southern Chile as Affected by 
Nitrogen Sources. From journal of plant Nutrition. 31: 1555-1569.

Faridah, E. 1999. Endomikoriza, Pengaruhnya terhadap Pertumbuhan dan Tingkat Ketahanan terhadap Kekeringan pada Semai Jati. Dalam Prosiding Seminar Nasional Status Silvikultur 1999. Fakultas Kehutanan Universitas Gadjah Mada. Hal: 243-247.

Garcia, I.V. \& R. E. Mendoza. 2008. Relationships among Soil Properties, Plant Nutrition and Arbuscular Mycorrhizal Fungi-Plant Symbiosis in a Temperate Grassland along Hydrologic, Saline and Sodic Gradients. In FEMS Microbiol Ecol 63:359-371.

Gumbira-Said,E. 1996. Prospek Pemanfaatan Bioteknologi untuk Penyediaan Pangan. 27 (VII). 30-36.

Leigh, J., A. Hodge. \& A.H. Fitter. 2008. Arbuscular Mycorrhizal Fungi can Transfer Substantial Amounts of Nitrogen to Their Host Plant from Organic Material. In Journal compilation. New Phytologist. 181: 199-207.

Limin, S. H., J.O. Rieley., H. Ritzema \& H. Vasander. 2008. Some Requirement for Restoration of Peatland in the Former Mega Rice Project in Central Kalimantan, Indonesia: Blocking Channels, Increasing Livelihoods and Controlling Fires. Dalam Proceedings of the $13^{\text {th }}$ International Peat Congress: After Wise Use-The Future of Peatlands. Volume 1. Edited by Catherine $\mathrm{F}$ and John Feehan. Tullamore, Ireland. Hal: 222-225.

Martin,E., Syaiful,I \& Teten,R.S. 2004. Pengaruh Endomikoriza dan Media Semai terhadap Pertumbuhan Pulai, Bungur, Mangium dan Sungkai di Persemaian. BPPK DEP Kehutanan. Jurnal Penelitian Hutan Tanaman. Vol 1. no 3. 87-131.

Maki, T., M. Nomachi., S. Yoshida. \& T. Ezawa. 2008. Plants Symbiotic Microorganisms in Acid Sulaft Soil: Significance in the Growth of Pioneer Plants. Jurnal Plant Soil. 310: 55-65.

Mendoza, R., V. Escudero. \& I. Garcia. 2005. Plant Growth, Nutrient Acquisition and Mycorrhizal Symbioses of a Waterlogging Tolerant Legume (Lotus glaber Mill) in a
Saline-Sodic Soil. In Plant and Soil 275: 305-315.

Mendoza, R., del Carmen, LM. \& I, Garcia. 2009. How do Soil P Tests, Plant Yield and $P$ Acquisition by Lotus Tenuis Plants Reflect the Availability of Added P from Different Phosphate Source. Nutr Cycl Agroecosyst. DOI. 10.1007/s10705-0089245-4.

Muin. A. 2003. Penanaman Ramin (Gonystylus bancanus Miq. Kurz) pada Areal Bekas Tebangan dengan Inokulasi CMA dan Pemupukan Fosfat Alam terhadap Bibit di Persemaian. Laporan Hasil Penelitian Hibah Bersaing XI. Lemlit. (Tidak dipublikasi).

Page, S.E., Rieley, J.O., Shotyk, O.W. \& Wiess, D. 1999. Interdependence of Peat and Vegetation in a Tropical Peat Swamp Forest. Phil. Trans. Royal Soc. London. Hal: $18885-1897$

Pidjath, C., Y. Setiadi., E. Santoso. \& M. Turjaman. 2007. Kualitas Bibit Acacia crassicarpa A. Cunn. Ex Benth Hasil Sinergi Bio-organik dengan Cendawan Mikoriza Arbuskula di Ultisol. Dalam Prosiding Kongres Nasional Mikoriza II. "Percepatan Sosialisasi Teknologi Mikoriza untuk Mendukung Revitalisasi Kehutanan, Pertanian dan Perkebunan". Bogor. 17-21 Juli 2007.

Prayudyaningsih, R. \& B. Santoso. 2007. Efektivitas Mikoriza Arbuskula terhadap Pertumbuhan Semai Bitti (Vitex cofassus Reinw). Dalam Prosiding Kongres Nasional Mikoriza II. " Percepatan Sosialisasi Teknologi Mikoriza untuk Mendukung Revitalisasi Kehutanan, Pertanian dan Perkebunan”. Bogor. 17-21 Juli 2007.

Ritzema, H., Limin, S.H., Kitso, KSN. \& Jyrki Jauhiainen. 2008. Canal Blocking Strategies to Restore Hydrology in Degraded Tropical Peatlands in the Former Mega Rice Project in Central Kalimantan, Indonesia. Dalam Proceeding International Symposium and Workshop on Tropical Peatland. Peatland Development: Wise Use and Impact Management. Kuching, Sarawak, Malaysia. Hal: 260-269. 
Saito.H., Shibuya. M., Tuah. S.J., Takahashi. K., Jamal.Y., Segah.h., Putir. P.E. \& Limin. S.H. 2002. Preliminary Selection of Fastgrowing Tree Species with Tolerance to an Open and Dry Peat Land in Central Kalimantan: To Develop a Preceding Planting Method. Dalam Proceedings of the International Symposium on Land Management and Biodiversity in Southeast Asia. Bali. Indonesia.Hal: 7579.

Santoso, E., Indry., A.W. Gunawan., K. Tawaraya. \& M. Turjaman. 2007. Early Colonization of Arbuscular Mycorrhizal Fungi in Tree Producing Gaharu Aquilaria microcarpa seedlings. Dalam Prosiding Kongres Nasional Mikoriza II. "Percepatan Sosialisasi Teknologi Mikoriza untuk Mendukung Revitalisasi Kehutanan, Pertanian dan Perkebunan". Bogor. 17-21 Juli 2007.
Shepherd, P.A., Rieley, J.O. \& Page, S.E. 1995. The Realitionship between Forest Vegetation and Peat Characteristics in the Upper Catchment of Sungai Sebangau, Central Kalimantan. Dalam; Biodiversity and Sustainability of Tropical Peatlands. Proc. Of the Int. Symp on Biodiversity, Environmental Importance of Trop. Peat and Peatlands. Editor: Rieley, J.O and Page, S.E, Samara publ. UK. Hal: 191210.

Turjaman, M., Saito. H., Santoso. E., Susanto. A., Sampang.G., Limin. S.H., Shibuya. M., Takahashi. K., Tamai. Y., Osaki. M. \& Tawaraya. K 2007. Effect of Ectomycorrhizal Fungi Inoculated on Shorea balangeran under Field Condition in Peat-Swamp Forest. Dalam Proceeding International Symposium and Workshop on Tropical Peatland. Carbon-ClimateHuman interaction- Carbon Pools, Fire, Mitigation, Restoration and Wise Use. Yogyakarta. Indonesia. 